\title{
'As if it Was Something Spoken by a Friend': The Study of Digital Vote-Canvassing Networks on Facebook During the 2013 Bangkok Gubernatorial Election Campaign
}

\author{
Mukda Pratheepwatanawong ${ }^{1}$
}

\begin{abstract}
Adapting the idea of the traditional vote-canvassing network for the analysis of electoral politics in the digital arena and using the concept of 'two-steps flow', this paper explores the way in which Facebook was used to establish and develop 'digital vote-canvassing networks' during the 2013 Bangkok gubernatorial election campaign, which was the latest and a completed election in Thailand. This paper attempts to answer the question 'How was the relationship among the individuals who were part of the candidates' networks on social networking sites developed during the 2013 Bangkok gubernatorial election campaign?' This research used multimodal analysis to determine the two main contenders' strategy in expanding their Facebook network during the 2013 Bangkok gubernatorial election campaign. This research also conducted a total of 14 semi-structured interviews with Thai politicians, election candidates and their public relations personnel to examine the significant of relationship, interaction and spreadability of content on SNSs during the election campaign. This paper argues that the development of relationships among people connected to the digital vote-canvassing networks was integrated through the coordination and dissemination of campaign content on Facebook to enhance the electoral ties between candidates, their followers and followers' friends, who might or might not be voters of the election. Vote-canvassing systems become 'digital' when a candidate's public relations personnel acted as core vote-canvassers who manage and transmit campaign messages on the candidate's Facebook page on behalf of the candidate, while the candidate's followers interacted and spread the candidate's campaign message to their own networks, enabling more Facebook users, who are connected to candidates' Facebook page, in one way or another, to be exposed to the campaign content. However, there is no guarantee of votes in the digital votecanvassing network.
\end{abstract}

Keywords: Digital Vote-Canvassing Network, Social Networking Sites, Algorithms, Spreadability, 2013 Bangkok Gubernatorial Election Campaign

\footnotetext{
${ }^{1}$ Researcher at Mekong Studies Center, Institute of Asian Studies, Chulalongkorn University, Thailand. She has a particular interest on Vietnam in relation to ASEAN connectivity, foreign investment, labour mobility, digital divide and social media. Her Ph.D. research, which was fully funded by The University of Nottingham, explored into political communication, election campaign and political public relations on social media in Thailand with the use of mixed methods. Corresponding e-mail: mukdapratheep@gmail.com
} 


\section{Introduction}

The 2013 Bangkok gubernatorial election campaign was an important election at local and national level, drawing major attention from politicians, voters and media who sought continuously to keep up-to-date with candidates' campaign. The fundamental question in the 2013 election was whether the winning trend of the Democrat Party in Bangkok gubernatorial elections since 2004 would be broken. The Democrats had struggled at the national level of election with pro-Thaksin parties winning elections in 2000, 2005 and 2011, and losing in the Bangkok gubernatorial election would consolidate the position of the pro-Thaksin side of Thai politics. The high level of competitiveness during the 2013 Bangkok gubernatorial election campaign was reflected in the different approaches and policies used by candidates. As a veteran of the elections, Mom Rajawongse Sukhumbhand Paribatra (M.R. Sukhumbhand) from the Democrat Party saw the importance of continuing to develop and implement policies which he had supported since the 2009 election, while the new candidate from the pro-Thaksin Phue Thai Party, Police General Doctor Pongsapat Pongcharoen (Pongsapat), characterised his campaign and policies under the slogan of 'to work with government seamlessly' and campaigned on uniting the administration of the capital with the central government. In a neck-and-neck competition, M.R. Sukhumbhand won the election, while Pongsapat came second. Candidates' use of social networking sites (SNSs) such as Facebook was a significant part of the election campaign as it played a key role in developing the candidate's network. This paper explores the nature of that role.

Regardless of the roles of different types of vote-canvasser, the networked relationships between the candidate, vote-canvassers and voters are significant in engaging and spreading information about the candidate from one vote-canvasser to another. Using media features identified by Baym (2010) (interaction, reach, temporal structure and mobility), traditional vote-canvassing networks in Thai political culture, two-step flow, this paper examines the networks of disseminating campaign messages in relation to the concepts of spreadability of content on SNSs and how interacting on SNSs could create and expand 'digital vote-canvassing networks'. With referenced to the author's previously published book chapter titled 'Uses of Social Networking Sites as a Development of Political Communication and Election Campaigns in Thailand', which discusses on media management as part of political public relations by looking 
at the relationship of content between candidate's SNSs page and campaign on the old media (Mukda, 2018), the research question for this paper is 'How was the relationship among the individuals who were part of the candidates' networks on social networking sites developed during the 2013 Bangkok gubernatorial election campaign?'

This paper sets out to identify the relationship among the individuals who are part of digital vote-canvassing networks, including candidate of the election, candidate's campaign staff, candidate's public relations personnel, candidate's followers and followers' friends, who might or might not be voters of the election. 'Digital vote-canvassing network' is a conceptual model that this paper will develop by integrating with the empirical data collected in this research. Thus, in order to meet this objective, this paper starts off by reviewing previous research on the use of social media for political communication and election campaigning in other context and explain the system of traditional vote-canvassing network in Thai political culture, the features and function of SNSs, particularly Facebook. Then, this paper moves on to characterize digital vote-canvassing network based on its function and its expansion through Facebook, together with the analysis on the roles of public relations personnel in order to visualise the candidates' networks based on the operation of the election campaign on SNSs and the plausibility for SNSs networks to interchange through the relationship among SNS users and their interaction on SNSs.

The notion of 'relationship management' is developed from online political public relations on SNSs as an important element to maintain the relationship between the election candidate and the followers. 'Political public relations' is defined by Strömbäck and Kiousis (2011) as 'the management process by which an organisation or individual actor for political purposes, through purposeful communication and action, seeks to influence and to establish, build, and maintain beneficial relationships and reputations with its key publics to help support its mission and achieve its goals' (p. 8). This research intends to apply the notion of political public relations to candidate's SNSs page, looking particularly at relationship management, in order to understand the network of communication on candidate's SNSs page.

This paper argues that the development of relationships among people connected to the digital vote-canvassing networks was integrated through the 
coordination and dissemination of campaign content on Facebook to enhance the electoral ties between candidates and voters. The spreadability of election campaign content posted on candidates' Facebook pages can increase the interchangeability of the digital vote-canvassing networks and strengthen the probability of voters voting for the candidate through the coordination and dissemination of campaign content and visual images on Facebook, management of human resources and relationships, which makes campaign message sound 'as if it was something spoken by a friend'.

The current research on digital vote-canvassing network and the 2013 Bangkok gubernatorial election was the latest local election in Thailand that candidates and voters make substantial use of SNSs. With the upcoming general election in Thailand expected to be in early 2019, the current research is significant for Thai political figures, candidates of Thai elections, public relations personnel, campaign staff and candidate's followers and voters of the election to deeply understand the evolution of vote-canvassing network when SNSs have been a fundamental part of election campaign in Thailand, which will allow all stakeholders involved in the election campaign to strategise their campaign network in order to achieve the objective of their campaign on SNSs as efficient management of digital vote-canvassing network has the potential to lead to political change or change in leadership.

\section{Interacting and Spreading of Messages on Facebook}

The concept of 'two-steps' flow of communication has been regarded as a fundamental communication concept that can spread and amplify messages among individuals and media on communication network. Research in different context had shown that two-steps flow of communication can increase the spreadability of message in the communication network. It could be said that vote-canvassing network is also developed from the concept of 'two-steps flow' of communication and has always been a significant part of Thai election campaign as candidates strive to establish and develop their relationship between candidates and voters with the primary objectives to gain votes during the polling day. The efficiency in facilitating and managing vote-canvassing network could also lead to the construction of image showing that candidates have large number of voters supporting the candidate's campaign. As communication technology develops, the notion of vote-canvassing network in Thai political culture still plays a fundamental role and act as a basis to 
spread messages on digital communication network, but need to be revised, which this research named such network as 'digital vote-canvassing network'.

'Digital vote-canvassing network' is a conceptual model that this research will develop with the integration of empirical data. This section will review previous research on the use of social media for political communication and election campaigning in other context and explain the system of traditional vote-canvassing network in Thai political culture and the features and function of SNSs, particularly Facebook. This is done in order to show that there is a gap of knowledge to understanding digital vote-canvassing network and the significance of such knowledge contribution will enable stakeholders of election campaign to make more efficient use of SNSs to gain support.

In the state election in North Rhine-Westphalia, Germany in 2010, Marcinkowski and Metag (2014) discuss that the idea of 'two-step flow of campaign message' occur in a way that candidate expect journalists to access the information that candidates published on Web sites and use it to communicate with voters who receive campaign information from traditional news media. Moreover, Copeland and Römmele (2014) discuss that people who receive campaign posts on social media acted as opinion leaders during the 2009 German Federal Election campaign as they were the intermediaries between the political party and the larger group of voters, for them to discuss political ideas with. Also, a few researchers have commented that the spreading of political content online and offline have created possibilities of gaining attention from less active voters as they get exposed to political content from people who they are related to. In the research that Norris and Curtice (2008) undertook about the flow of political messages on the internet during the 2005 British general election, they found that the more sources of political information that someone used to search about the election, the more likely that person would talk about the election to someone who might not use the internet to acquire information themselves.

In another study on the effect of social media on political participation and candidate's image evaluation in the 2012 Iowa caucuses, Dimitrova and Bystrom (2013) noted that when citizens compose and post political messages on the internet, this can lead to the possibilities to affect political outcomes as social media are able to influence citizens' perception of the candidates. This implies that even though nothing has been found in relation to the direct influence of spreading political content on 
voting decisions, the internet is an additional source of political information for opinion leaders, who are very likely to disseminate political information to friends and family members around them. Such friends and family members might rely on these opinion leaders to give them information about the election.

With regards to vote-canvassing network, Sombat (1993) characterises votecanvassers as people who are respectable, responsible and related to the candidate in one way or another and are well-known in the community (p. 119). Anek (1996) identifies vote-canvassers in rural areas as village heads, landlords, shopkeepers, and school teachers, who are personal supporters of the candidate. These people act as village representative of political figures, and political figures have vote-canvassers to assist them in elections and keep in touch with voters (p. 206). Selecting the 'wrong' canvassers can cause the candidate to lose elections (Surin and McCargo, 1997, p. 138). Campaigning in a traditional vote-canvassing system consists of a multiple-layer of relationships in offline communication, introducing a candidate to more voters and exposing more voters to the candidate's campaign. Based on a study of the campaign of a candidate (Kom) in suburban Bangkok in 2005, Anyarat (2010) found that there were three layers of vote-canvassers i.e. core vote-canvassers, intermediate votecanvasser, and cell vote-canvassers, being responsible for different task. Ockey (2004) defines the literal meaning of 'vote-canvassing system' as 'vote-chief system' (p. 27). Callahan and McCargo (1996) state the literal meaning of vote-canvassers or hua khanaen as 'head vote' who act practically as canvassers, vote gatherers and vote banks. The electoral ties of vote-canvassers lie under the notion of the vote-canvasser distributing money or gifts to ensure that voters vote for the particular candidate that the vote-canvasser is working for, and the vote-canvasser can somehow determine the number of votes that the candidate will get in the election at specific locales (ibid.). Callahan and McCargo give an example of vote-buying that prevents voters from betraying vote-canvassers: the vote-canvasser buys the vote and 'hires' the voter's identification card, which agents of the vote-canvasser can use to pretend that they are voters (p. 387).

As communication technology develops, the idea of vote-canvassing network and two-step flow has been integrated into the way people are connected on SNSs and the way messages are disseminated on SNSs. As defined by boyd and Ellison (2008), SNSs are 'web-based services that allow individuals to (1) construct a public or semi- 
public profile within a bounded system, (2) articulate list of other users with whom they share a connection, and (3) view and traverse their list of connections and those made by others within the system. The nature and nomenclature of these connections may vary from site to site' (p. 211). SNSs such as Facebook consists of algorithms, or what Potter (2012) defines as 'a set of mental codes that people use both consciously and unconsciously to make sense of media messages' (pp. 26-7). Algorithm is the core element to clarify how people encounter and process media messages (ibid.).

Dubrofsky (2011, pp. 120-1) describes a user's Facebook home page as 'a moving, changeable space infused with particular digital tracks of a user's data movements', where Facebook makes announcements and acknowledgments of the interactions and status that the user just posted. Facebook's algorithm determines which post comes as the top news feed on a user's Facebook page. If a post is interesting and manages to gain a high level of interaction, it is likely that the post will be circulated on Facebook. Thus, the core idea of Facebook is to influence its users by continuously uploading data for other users to pay attention to (by commenting on it, clicking the 'like' tab or sharing the content).

With regards to interaction on Facebook, Van Dijck (2013) mentions that the literal meaning of the 'like' tab on Facebook is a reflection of people's preferences for things or the particular interest that they have as the amount of 'likes' that a piece of data receives can determine the level of interest (p. 158). When other users see what their friends 'like' on Facebook, it is possible for the content to have an impact on the user as they would be interested in relating themselves to the content that is of interest to their friends on Facebook (ibid.). As a result of the high level of interaction, Dubrofsky comments that a Facebook user's page can be completely 'transformed' overnight in response to the amount of interaction that a piece of content gets. New actions taken by a user's friends are shown on the page, moving notices about previous actions down the page even though users can retrieve old actions (Dubrofsky, 2011, pp. 120-1).

In terms of 'friends' on Facebook, Baym (2010) notes that there is no clear definition of who are friends on SNSs, since friends on SNSs can consist of 'strangers, admirers, confidants, co-workers, family and a host of other relationship types.' (p. 145). Offline friends can also be friends on SNSs. Moreover, depending on the culture and user's personality and choice, communicating online can both enhance and 
weaken relationships among users as the comfort level varies from one user to another (ibid., pp. 130-45). With SNSs, Miller (2011) states that people can communicate and stay in touch with one another in a faster and more direct form of communication. Moreover, Facebook is able to figure out how users are related to each other e.g. having a feature called 'People You May Know (PYMK)' to help users to find friends and flagging people whom users may be interested in adding to the network of people who are from same family or education institution (Van Dijck, 2013, p. 47, p. 156). This quality is what Van Dijck refers to 'connectedness' as Facebook guides users to share information with other users through 'purposeful designed interfaces' (pp. 46-7). With reference to Granovetter's (1973) analysis of strong ties and weak ties, it could be said that PYMK can be acquaintances and when Facebook users connect to PYMK, the connection might be a 'weak tie.' As Facebook friends are related differently to the Facebook user, the status updates of Facebook users is communication with multiple weak ties (Baym, 2010, p. 135). Whereas 'strong tie' relationships are established when Facebook users connected to their close friends (or when weak ties become converted to strong ties through interaction). Consequently, using SNSs enables users in various relationships to connect with one another through status updates, interaction and instant messages.

Interacting on a Facebook post brings the possibility for the content to be spread to other SNSs users. According to the definition provided by Jenkins, Ford, and Green (2013), the terms 'spread', 'spreadable', or 'spreadability', are used to describe 'the increasingly pervasive forms of media circulation' (p. 3). To be specific, 'spreadability' refers to the 'potential -- both technical and cultural --for audiences to share content for their own purposes, sometimes with the permission of rights holders, sometimes against their wishes' (ibid., p. 3), which means that once people have the content, they can spread it and the spreading of content on SNSs might occur for various reasons, intentionally or unintentionally. For example, after a Facebook friend posted a picture, the 'share' tab underneath the photograph allows users to 'share' publicly and privately (Miller, 2011, p. 75). The sharing of content and the notion of 'connectedness' of Facebook that Van Dijck (2013) mentions, enables shared content to appear as a news feed on a third person's Facebook page, allowing the third person to view and also to further 'share' the content. The spreading of content on Facebook can also be done by users clicking the 'Like' tab or leaving a comment on the post. Depending on 
the Facebook algorithm, there is a possibility that information about either of these actions will appear on the user's friend's timeline showing that the user had interacted and how the user interacted. Andrejevic (2006) as cited in Humphreys (2011, p. 577) states that the user can act as 'literal surveillance' to monitor the friend's interaction on his/her Facebook timeline. This can occur if Facebook does not notify the user's news feed of the friend's interaction. In other words, the spreading of content and the users interacting with the content is one of the social media features that Kent (2010) outlines, mentioning that users can construct and develop a network of anonymous 'friends' by sharing information on their network (p. 647). This means that communicating on SNSs has the potential for one message to reach and be spread to people who are connected directly or indirectly to the individual who makes the initial post.

The concepts of two-step flows and traditional vote-canvassing systems in election campaigns remains important in understanding the spreadability of campaign content but it should be updated in the context of technological development. It could be said that SNSs features of algorithms, interaction and spreadability of content have potential benefits for expanding candidates' SNS networks and getting direct access to followers' feedback, enabling candidates to know followers' thoughts based on the political issues that they have posted, while the backdoor operation of campaign staff and public relations personnel co-operating to send out messages on SNSs during an election campaign is vital to manage human resources to manage candidates' SNS pages. SNSs provides an opportunity for followers to interact about candidate's campaign and has the potential to spread candidates' campaigns on SNSs from one user to another.

\section{Data Collection and Research Methods}

\section{Multimodal Analysis}

In terms of research methods, multimodal analysis and interviews were used for data collection. Kress and Leeuwen (2006) define 'multimodal texts' as 'any text whose meanings are realized through more than one semiotic code' (p. 177). Jewitt (2009) says that the approach of multimodality to understanding communication and representation beyond the language used in communication takes into consideration other communicational forms that people use, such as image, gesture, and posture (p. 
14). A multimodal analysis was conducted by studying the official Facebook pages of the two main contenders in the 2013 Bangkok gubernatorial election (M.R. Sukhumbhand and Pongsapat) in order to determine the candidates' strategy in expanding their Facebook network during the 2013 Bangkok gubernatorial election campaign with reference to the way in which Facebook function as an interactive tool of communication that candidates have control on. The multimodal analysis adopted in this research consists of basic content analysis, framing analysis and semiotic analysis taking into account of traditional features of visual and linguistic communication as well as the multimodal elements of Facebook as an internet artefact and SNSs.

Content analysis allows a large number of communication materials to be analysed in a precise and systematic way, enabling researchers to make an objective judgement (quantitative content analysis) and subjective judgement (qualitative content analysis) on the communication text (Burnham, Gilland, Grant, and LaytonHenry, 2004). The strength of content analysis is that it provides a numerical overview of the results (Grbich, 2013).Such analysis allowed this research to gain raw material in the form of content communicated during the election campaign and to quantify data into different themes, based on how relationship can be built through policyrelated posts and non-policy related posts, languages and visual images selected, the time of the day that candidate publish different posts throughout the election campaign.

This research used Nvivo 10 software to capture and download M.R. Sukhumbhand's and Pongsapat's Facebook pages, from 14 January 2013 to 4 March 2013 , divided into 4 phases of the election campaign, with a total of 460 photographs and 469 posts from M.R. Sukhumbhand's Facebook page and 348 photographs and 404 posts from Pongsapat's Facebook page. Nvivo 10 does not only navigate and organise both qualitative and quantitative data, but was able to capture SNSs content for research purposes. The pilot study of this research was done on Pongsapat's Facebook posts. A total of 150 posts on Pongsapat's Facebook were used as the sample for the pilot study.

In terms of a coding scheme, the visual images studied in this research were coded according to the scheme of Grabe and Bucy (2013): 1. the Ideal Candidate; 2. the Populist; 3. sure loser. This research does not use the 'sure loser' image as 
candidates are unlikely to post a negative image on their SNS pages (Goodnow, 2013). The semiotic analysis also takes into consideration of signs of election campaign used as part of their identity during the election campaign, the colours that they used to edit their visual images, SNSs sign and candidate's SNSs username. This is done in order to determine how candidates construct their image in relation to other signs associated to their campaign.

To sum up, the multimodal analysis was adopted to explore the textual and visual content of candidates' Facebook pages in relation to the way in which candidates set their agenda-related policies over the period of the election campaign and the specific frames which candidates adopted to promote a particular image and aspect of their campaigns. Results of the multimodal analysis provide an overview of the campaign messages that candidates communicated and the images that they constructed and developed. What is still lacking is the justification for the operation of candidates' SNS pages; interviews.

\section{Elite Interviews}

According to Gillham (2000), an 'elite' is someone who is in a privileged position in terms of knowledge and expertise (p. 81). Burnham et al. (2004) propose that elite interviews will enable researchers to gain new ideas, distinctive viewpoints and interpretations related to the central research question and research framework ( $p$. 29). 14 semi-structured interviews with Thai politicians, candidates of the 2013 Bangkok gubernatorial election and their SNS public relations personnel were also conducted to examine the significant of relationship, interaction and spreadability of content on SNSs during the election campaign by discussing with them about their motivation, experience and challenges that they faced while using Facebook as an interactive communication in spreading their campaign online. Thus, interviews were conducted to gain further information on the operation of SNSs.

Chapter 1 The interview questions were open-ended, allowing interviewees to express their opinion fully. Due to the different experience and professional background of the interviewees, semi-structured interviews were used. According to Braun and Clarke (2013), a semi-structured interview is one where the researcher has prepared a list of questions based on the research scope, but interviewees are allowed to raise issues that the researcher has not anticipated. This type of interview allows other matters to emerge in the interview, enabling the research to capture the range of participants' responses. Burnham et al. 
(2004) propose that semi-structured interviews are the most efficient way to obtain information about decision-making processes. Therefore, as this research aims to analyse the different experience of interviewees using SNSs in the election campaigns, semi-structured interviews allowed a range of individual issues to be examined in detail.

The coding process for interview transcripts was done in two steps. Firstly, interview transcripts were printed out, and the researcher became familiar with the data by actively and analytically reading through it. Based on the background knowledge the researcher had about each candidate studied in this research, the researcher wrote notes beside interesting answers or comments. By becoming familiar with the data in such way, the researcher was able to think critically about 'what the data mean', which is part of the basic qualitative coding procedure proposed by Braun and Clarke (2013). Secondly, all interview transcripts were coded 'selectively' on Nvivo 10 software to identify aspects of the data in relation to the research questions. According to Braun and Clarke (2013), the aim of selective coding is to determine the data which the research is interested in analysing and this was done to reduce the quantity of data and to focus on identifying anything relevant to this research. Also, 'researcher-derived' (ibid.) codes were also used to identify implicit meaning in the interview transcripts, with the assumption that interviewees might not truly express their challenge in using SNSs during the election campaign.

As mentioned previously, the characteristics of digital vote-canvassing network that this paper will develop is an integration of a conceptual model and empirical model that has literature on the features and function of SNSs and traditional votecanvassing network set as the analysis. Such knowledge was used to guide the current research for data collection, which the current research was able to identify, analyse and highlight the characteristics of digital vote-canvassing network in the following section.

\section{Digital Vote-Canvassing Networks}

This paper uses a prototype to discuss how the management on the flow of campaign information on Facebook and the relationship between individuals who are part of the candidates' campaign on Facebook can establish and expand their digital vote-canvassing networks. Analysis will start by looking at the role and relationship of public relations personnel and candidates establish a digital vote-canvassing 
network, which is a development from traditional vote-canvassing systems. Then, this paper moves on to envisage the expansion of digital vote-canvassing networks by reviewing the benefits and implications of followers interacting and spreading candidates' campaigns on SNSs.

\section{Establishment of digital vote-canvassing networks: Core digital vote-canvassers on Facebook}
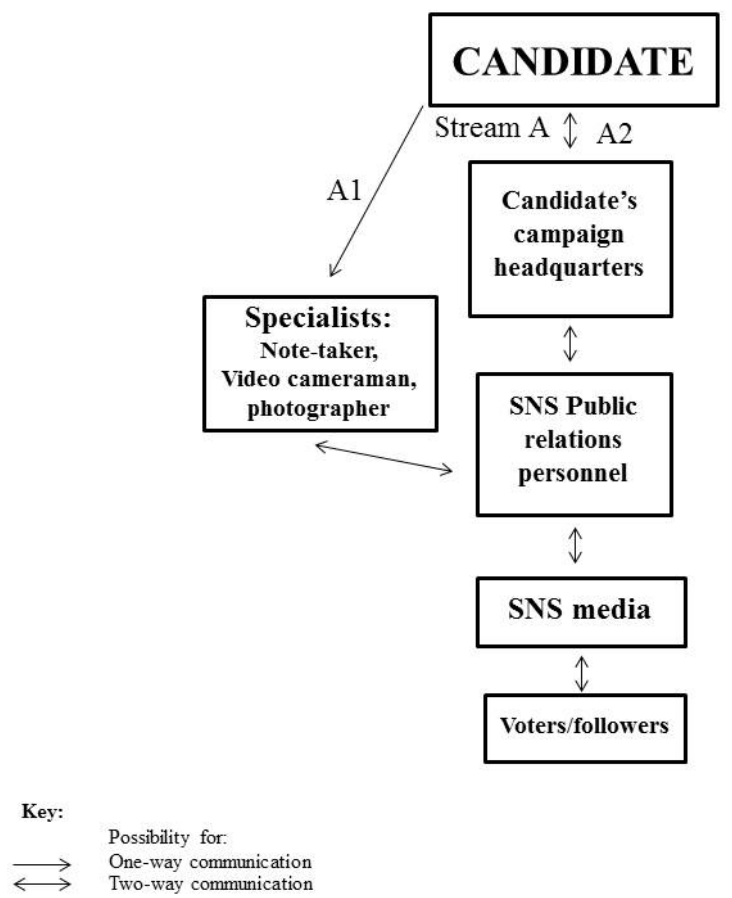

Figure 1. Flow of information on SNSs between candidates who use public relations personnel to transmit campaign messages to followers

(Source: Author's compilation)

Figure 1 is a prototype of the transmission of election campaign message flows from candidates to followers on SNSs, which consist of:

1. Candidate.

2. Candidate's campaign headquarters: On Stream A2; the people who disseminate campaign information from the candidate to other channels of communication.

3. SNS public relations personnel: Campaign staff who post messages on behalf of the candidate on SNSs.

4. SNS media: SNSs as media platforms where campaign messages between candidates and followers are transmitted and exchanged. 
5. Voters/followers: Voters in the election or followers of candidates who are SNS users.

6. Specialists: On Stream A1; note-takers, video camera operators and photographers who keep a record of candidates' movements. These specialists send their work to public relations personnel to select content to be posted on candidates' SNS pages.

As shown in Figure 1, personnel use Facebook to make the connection between candidates and followers. This part finds that the prominent role of candidates' public relations personnel and their relationship with the candidates have developed on the framework of traditional vote-canvassers in Thai election campaigns, turning personnel into 'digital vote-canvassers,' who operate 'digital vote-canvassing networks'. There are parallels between the roles of digital vote-canvassers and traditional vote-canvassers in Thai election campaigns.

Public relations personnel or digital vote-canvassers were a type of in-house vote-canvassers during the election campaign on SNSs. They are related to the candidate of the election in a way that they can act on behalf of the candidate in various roles, playing a significant role in managing and personalising candidates' SNS pages during the 2013 Bangkok gubernatorial election campaign. Before the election campaign and during the first period of the election campaign, both public relations personnel and the candidate of the election frequently communicate with each other as the public relations personnel had to understand about candidate's background, policies and the way that the candidate interact with voters. However, as the election campaign preceded, public relations personnel have more autonomy and independence to work on candidate's SNSs page. With the intention to influence voting decisions, both digital and traditional vote-canvassers have specialised demographic knowledge on their electorates and target groups with whom they are communicating and both types of vote-canvassers play an intermediary role in linking candidates and voters during the election campaign.

However, traditional vote-canvassers obstruct other candidates' campaign movement in villages and rig election results (Phichai Rattanadilok Na Phuket, 1998, pp. 167-168 ascited in Anyarat, 2010, p. 72), which makes the work on digital votecanvassers a development from the traditional vote-canvassing network. This research found that digital vote-canvassers monitored other candidates' Facebook 
pages by noting whether other candidates mentioned anything about their candidate in a positive or critical way. This was done so as to be aware of the candidate's competitors attempt to acknowledge or attack them during the election campaign. Links between candidates and different campaign staff led to the collaboration among campaign staff in the digital vote-canvasing networks. The head of the public relations team had regular contact with the candidate during the election campaign, and the head would provide the candidate with a daily report based on what has been posted and follower's interaction on the candidates' SNS page. The outer layer of the digital vote-canvassing network (Stream A1 of Figure1) consisted of different specialists, namely note-takers, video cameramen, and photographers recording what happened during the candidate's field campaign, while editors in another location edited photographs and video, with their finished products sent through the internet to the head of public relations team. The head of public relations team was able to compose a message and publish it on the candidate's SNS page based on the strategic communication plan initially defined for the election campaign.

There are differences in the temporal structure of communication among traditional vote-canvassers and digital vote-canvassers. Communication in traditional vote-canvassing networks was mainly through face-to-face meetings and telephone calls, but communication with digital vote-canvassers, campaign staff or specialists was mainly made by e-mail and instant message applications such as Line and WhatsApp, which were practical only with internet connections. Depending on internet connection and how people are notified about the message transmitted, the temporal structure on the digital vote-canvassing networks is an asynchronous communication as there might be delay between the time the sender sends the message and the receiver gets or reads the messages (Baym, 2010). Arguably, communication in digital vote-canvassing networks is real time in terms of updating the message on computer screen and the ability to extend its reach to more SNSs users. Communication between digital vote-canvassers and followers was made through different SNSs such as Facebook, Twitter, Instagram and Google Plus, which also require an internet connection, making the speed of communication in digital votecanvassing network faster than in traditional ones. On the screen, communication between the candidates and their followers might seem 'short' and 'direct' but there was a hierarchy of teams acting behind the screen to publish posts on SNSs. One 
possible explanation for this is the digitalisation of communication on digital votecanvassing networks, allowing rapid communication on candidates SNS campaigns though several staff campaign were in different locations during the election campaign.

The different form of communication used in traditional and digital votecanvassing networks defined the sub-duties of campaign staff connected to digital vote-canvassers. Digital vote-canvassers acted on behalf of candidates to personalise communication on candidates' SNS pages by structuring individual posts to suit the timeframe of the different phases of the election campaign as well as to target followers. As a result, digital vote-canvassers coordinated and built online networks using their specialised knowledge of followers or voter segmentation and decided on the strategies to use on SNSs. Communication strategies on SNSs have been used to influence voting decisions through the basic idea of microtargeting (Bimber, 2014; Edgerly et al., 2013; Stokes-Brown, 2012). Given that followers can follow more than one candidate's SNS page and the existence of swing voters in the 2013 Bangkok gubernatorial election (Boonlert, 2015), it was important for digital vote-canvassers to make SNSs personalised channels of campaign communication to reach voters' needs, engage with them and persuade them to vote for the candidate. In other words, digital vote-canvassers had to ensure that candidate's campaign was relevant to voters, and they had to be able to sustain their attention throughout the election campaign.

In short, the backdoor operation of election campaigns on SNSs indicates that political public relations on SNSs during the election campaign developed from traditional vote-canvassing networks based on the roles of vote-canvassers and their relationship with candidates, which established digital vote-canvassing networks through a different temporal structure of communication, enabling more rapid and centralised management of human resources and communication on SNSs during the 2013 Bangkok gubernatorial election campaign. Personnel become core digital votecanvassers, playing a significant role in communicating with candidates and their followers, with the use of different campaign staff specialists collaborating to send out campaign messages on candidates' SNS pages. 


\section{Expansion of Digital Vote-Canvassing Networks: Making Facebook Friends Become Part of Digital Vote-Canvassing Networks}

Elaborating from the establishment of digital vote-canvassing networks, this paper moves on to demonstrate how candidates' followers and followers' friends can be part of the digital vote-canvassing networks through interaction on SNSs, particularly Facebook and how interaction can expand the digital vote-canvassing network.

Interaction on candidates' Facebook pages during the 2013 Bangkok gubernatorial election campaign was initiated in two ways. The first type is that regardless of the content of posts, every Facebook post had a certain level of interaction via clicking 'Like', 'Share' or commenting. The second way is when candidates directly encourage followers to interact on particular post or particular topic as candidates seek followers' opinions on an issue. In other words, candidates posted to initiate interaction on Facebook, encouraging followers to click 'Like', 'Share' or commenting on campaign content. The interaction feature of SNSs seems to be a beneficial communication feature for followers to express their opinions on different agendas and for candidates to receive feedback about their campaigns on SNSs. Allowing followers to interact is a way to establish and build a relationship between candidates and followers.

A public relations staff member working for an independent candidate expressed her concern about the lack of public opinion in Thailand and she viewed SNSs as an appropriate space for people to voice their views on different issues. Therefore, she attempted to set an appropriate communication strategy on the candidate's SNS page for followers to feel comfortable in interacting with the candidate. She explained that the value of using SNSs in the election campaign is to make the best use of two-way communication to gain the most benefit for the candidate and the followers. Unlike having a large number of followers clicking 'Like' on candidates' posts and photographs, the public relations personnel stressed the value of interaction between the candidate and his followers, by asking followers to post their opinions on different problems in Bangkok and critically analysing the problems from various perspectives. Being interactive and receiving public opinions seemed to be important for candidates because candidates were able to know the voter segmentation and voters' opinion, which enabled social networking platform to 
be used to its full potential during the election campaign. Also, it could be said that interactive posts can be used to portray the candidate's image as having the potential to be the Bangkok governor, willing to listen to Bangkokians' problems and thoughts. However, there are doubts about whether candidates valued the social issues or comments that followers posted on the candidates' SNSs pages, which means that candidates might be using SNSs to construct an image of being concerned with the problems that followers face, without actually paying attention to the content of interaction.

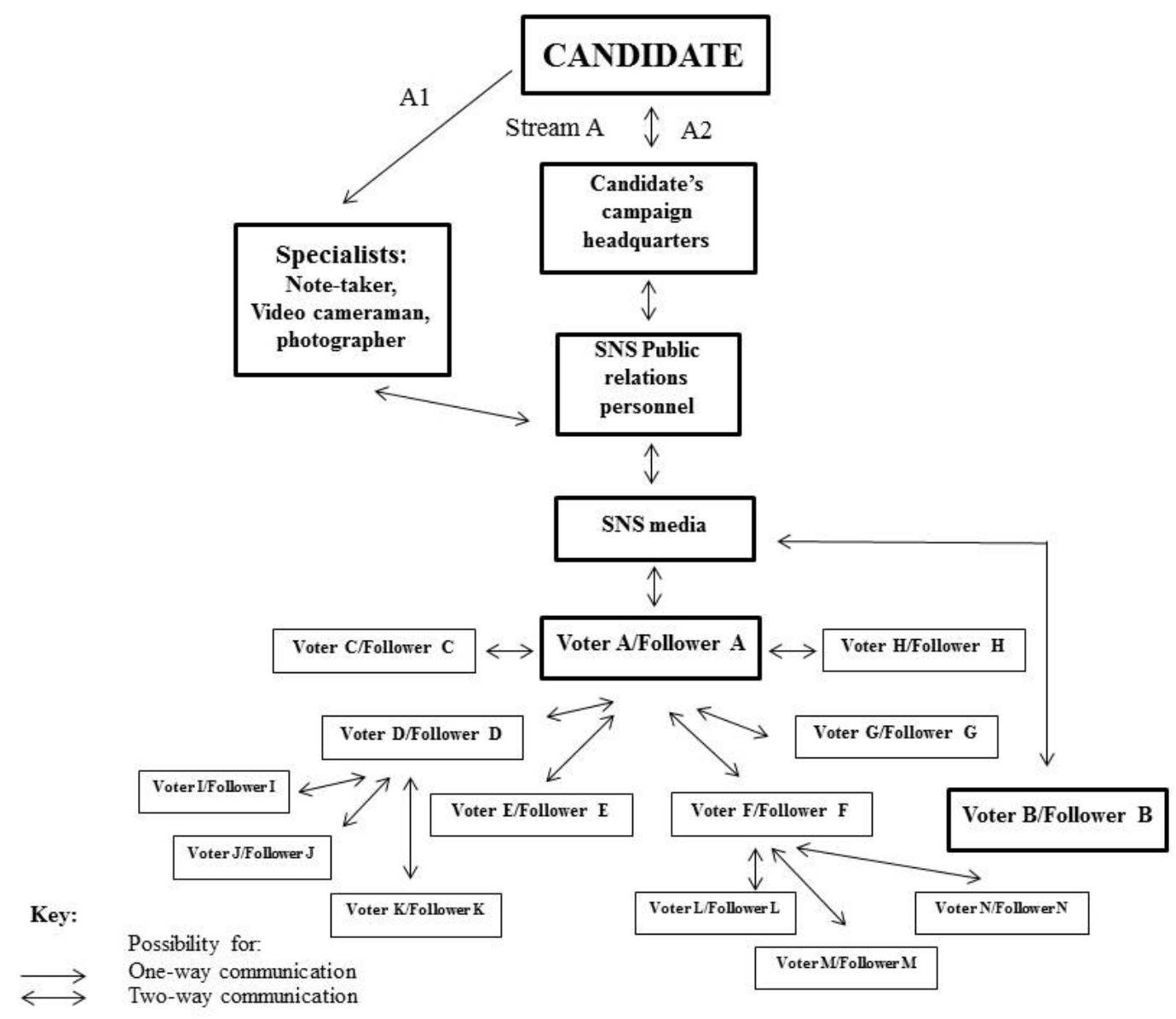

Figure 2. Voters as vote-canvassers through interaction on social networking sites.

(Source: Author's compilation)

With reference to Van Dijck's (2013) concept of 'connectedness' (pp. 46-7), interaction on Facebook would allow Voter A on Figure 2 to spread the digital votecanvassing network. In Figure 2, Voter A and Voter B are followers of the candidate on Facebook, and received campaign information directly from candidates on Facebook. After Voter A received a post from the candidate and if he decided to interact on the post, whether through sharing, clicking on the 'Like' icon or making a comment, 
friends of Voter A would be able to see the candidate's campaign content and the type of interaction by Voter A. In other words, the candidate's campaign content and the type of interaction would appear on news feeds of Voter A's friends, who are Voters C, D, E, F, G, and H. Assuming that Voters D and F continue to share the post with their Facebook friends, Voters I, J, K, L, M and N would also receive the campaign message. The interactive features of sharing Facebook posts, therefore, increase the visibility of candidate's posts to followers' friends, which expands the flow of information from a follower to a non-follower in the candidate's Facebook page. If this continues, the campaign information will spread to more Facebook users who are non-followers of the candidate. Conversely, Voter B, who is a passive follower of the candidate, did not interact on the post, which means that Voter B's friends would not receive the campaign message on this network.

The different ways of interaction indicate different intentions of followers spreading a candidate's campaign message on Facebook. For example, if Voter A shares the post, the content would spread to Voter A's friends' news feed and will also be shown on Voter A's Facebook timeline. If Voter A makes a comment on the post, Voter A is 'unintentionally' spreading the post to his friends on the network. Depending on the Facebook algorithm to prioritise news feeds, Voter A's friend might be notified on the news feed that Voter A has made a comment on the candidate's post, which Voter A might not know about. However, if many followers leave comments on the same post at the same time, the comments that Voter A made might be hidden but would be visible to viewers who search to filter all the comments posted on the individual post. Consequently, Voter A was 'unintentionally' increasing the candidate's visibility on Facebook as Voter A might not know that making a comment on the post would be acknowledged on Voter A's friends' news feeds according to the Facebook algorithm. This effect also applies when Voter A clicks 'Like' on a post. At this point, however, what is known is the number of interactions at the initial stage, which is the number of active followers who interact on the candidate's post. Voter A would not know if Facebook friends of Voter D and Voter F continued to interact on the post at the outer layer of the network, but we can assume that a few will continue to do so.

The multiple layers of interaction by different Facebook users connected directly and indirectly to candidates' Facebook pages expand the digital vote-canvassing networks. This expansion constitutes the notion of Jenkins et al. (2013) spreadable 
media content on SNSs from one user to another, and Kent's (2010) proposal of interchanging networks via interaction, making campaign messages reach more users, which further reflects the notion of two-step flow in circulating campaign information through interaction (Katz and Lazarsfeld, 1955). With further reference to how Marcinkowski and Metag (2014) state that 'two-step flow of campaign message' in the state elections in North Rhine-Westphalia, Germany in 2010, occurs by candidates expecting journalists to use candidates' campaign information on Web sites to further spread on traditional news media, this research found that the idea of two-step flow on Facebook were significantly associating with followers interacting and spreading candidate's campaign content. Followers of a candidate's Facebook page are the online opinion leaders while friends of such followers on Facebook are a less active group of voters who do not seek to gain campaign information directly from candidate's SNS page and the spreadability of candidate's campaign on Facebook is not restricted to time.

Online opinion leaders might also conduct interpersonal communication offline with friends and family who are not friends of opinion leaders on Facebook. Thus, candidates' followers who interact with candidates' campaign content on Facebook might spread the content to their online or offline friends in a two-step flow manner. If the content continues to spread, the multiple-step flow of campaign messages will reach other voters who are indirectly connected to the digital vote-canvassing networks. Therefore, when candidates encouraged followers to interact directly about the candidates' campaign on Facebook, they were implicitly asking followers to expand their digital vote-canvassing networks. From this point, it could be said that the candidate perceived followers as 'digital vote-canvassers' while followers who interacted on candidates' Facebook pages were indirectly becoming part of the candidates' digital vote-canvassing networks, which they might be willing or unwilling to do. The spreading of campaign information on Facebook becomes more complex in the outer layers of the digital vote-canvassing networks as there is no information about where campaign messages are heading and where the flow of information ends.

The multiple-flow of communication on digital vote-canvassing networks is individualistic, enabling candidates and voters or voters' friends to establish a more direct and personal relationship. In campaigns that did not contain any encouragement to followers to interact, a certain level of interaction on candidates' 
Facebook could be beneficial in spreading campaign content on SNSs. Followers who left critical comments on candidates' SNSs pages were challenging the candidates' image, and SNSs allow such content to be further spread to other users.

The relationship between the outer layer of digital vote-canvassers and candidates was not a long-term relationship because such relationship was focused mainly during the election campaign, which was 42 days (from the official start of election campaign, 21 January, till the day before the election campaign, 2 March 2013). This means that candidates and their public relations personnel had to devote their time and attention to delivering their campaign messages on SNSs to different groups of followers in a short period. Thus, it must be stressed here again that public relations personnel played a crucial role in structuring the posts and continuously encouraging followers to interact on the posts, which built the relationship between candidates and followers as well as other SNSs connected to followers.

Above all, there was no evidence found about how campaigns on SNSs can guarantee votes from followers. A public relations personnel attempted to explain that there is still insufficient evidence to show that the use of SNSs cause election results. This means that the number of supporters that candidates gained on SNSs could not be used to indicate or predict the number of votes that the candidate will get in the election. The public relations personnel justified this by saying 'social media numbers in Thailand are not that great yet', which implies that the digital divide in Thailand had limited the ability to use SNSs to predict election results. Hence, the use of SNSs for the election campaign and political communication cannot involve the whole Thai population.

As discussed previously, Callahan and McCargo (1996) noted the literal meaning of hua khanaen is 'head vote', while hua khanaen act in practice as canvassers, vote gatherers and vote banks. The distribution of money and gifts to rural voters could be used to predict or indicate the number of votes that candidates would get under the patron-client relationship. With reference to Hutton's (1999) claim that public relations is 'managing strategic relationships', the management of relationships between candidates and followers on SNSs during the election campaign is 'strategic' as the primary goal of candidates is to win the election by utilising SNSs to spread their campaign messages to reach voters. However, other than knowing the reaction that candidates receive to their campaign message on SNSs, there has been no way to 
determine the relationship between campaigning on SNSs and the number of votes that candidates would get. The transformation of campaigning on digital technology allows more diverse groups of SNSs users to connect to candidate's SNSs network. Followers of candidates' SNS pages might be voters or non-voters of the election and followers can also follow more than one candidate to access direct communication channels with the candidate. This suggests that SNSs have moved vote-canvassing systems into the direction where SNS users of various backgrounds are connected to candidates' SNS networks without having any electoral tie with the candidate. Consequently, campaign strategy on SNSs becomes more challenging as SNS users connect to candidates' networks for various reasons. There was no way for candidates or their staff to guarantee that campaigning on SNSs could affect voting, and this finding supports previous researchers who had commented on this (Hansen and Kosiara-Pedersen, 2014; Nalinee and Brown, 2006; Strandberg, 2013).

To summarise, the features of Facebook had leaded to the establishment, expansion and development of digital vote-canvassing networks through different Facebook users who are connected to candidates' Facebook networks in one way or another, through continuous interaction on candidates' Facebook pages. The interaction of followers on candidates' Facebook pages was another fundamental part of the election campaign on Facebook as it increased the spreadability of campaign content and maximised candidate presence on Facebook during the election campaign for other Facebook users to take into consideration. Followers who interacted on campaign content that they received directly from the candidates' Facebook pages can be considered as the outer layer of digital vote-canvassing networks. Therefore, the interaction features of Facebook are especially beneficial for new candidates with a small number of followers. Efficient management of interaction on Facebook can expand and develop digital vote-canvassing networks through the way people are related to each other, which might or might not influence voting decisions but increases candidates' visibility, allowing campaign messages to reach more Facebook users. 


\section{Conclusion}

To answer the question that was proposed in the abstract and the introduction of this paper: 'How was the relationship among the individuals who were part of the candidates' networks on social networking sites developed during the 2013 Bangkok gubernatorial election campaign?, and with the research methods employed in this research, the main finding of this research are: Firstly, the relationship between the candidates and followers was developed through the professionalization of candidates' public relations personnel in managing campaign content on behalf of the candidate, who plays a fundamental role in selecting and framing election campaign content and regularly posting the content on candidate's Facebook page. Secondly, in terms of the relationship between the candidate and public relations personnel, public relations personnel acted as core vote-canvassers to co-ordinate campaign message on SNSs, to communicate with followers as well as to encourage followers to spread the candidates' campaign on SNSs, indicating that candidates allowed public relations personnel to have independence and autonomy to enhance their image on SNSs during the election campaign. The findings in this research are developed from the traditional vote-canvassing networks in Thai political culture (Anek, 1997; Anyarat, 2010), spreadable media (Jenkins et al., 2013) and the two-step flow (Katz and Lazarsfeld, 1955), under the features of interaction, reach, temporal structure and mobility that Baym (2010) identifies and interchangeability of networks that Kent (2010) outlines.

To conclude, in the context of the use of Facebook for 2013 Bangkok gubernatorial election campaign, this paper argues that the establishment and development of relationships among people connected to the digital vote-canvassing networks was integrated through the coordination and dissemination of campaign content on Facebook to enhance the electoral ties between candidates, their followers and followers' friends, who might or might not be voters of the election. Thus, digital vote-canvassing network constitutes of political public relations work of relationship management that establish and expand the network of candidate's SNSs page through the organisation and spreading of campaign content on SNSs and increasing the exposure of content to as many SNSs users as possible in a short period of time. Digital vote-canvassing network is a new form of vote-canvassing network which operates through a new channel of communication that is SNSs, and have the element of digital vote-canvassers performed the same function as the traditional vote-canvassing 
network with the intention of bringing voters to make a decision. However, there was no evidence found in this research on how this could be guaranteed or measured from campaigning on SNSs.

Although the mediation on SNSs cannot ensure that followers will support candidates through voting, but the relationship of people connected on digital votecanvassing network, the decentralisation of communicating and the spreading of messages on SNSs provide a significant opportunity for the messages to be circulated to more SNS users, enabling more SNSs users to recognise the image of candidates and enabling candidate's campaign to be introduced to more SNSs users, which could lead to the possibility for political figures to gain support. The algorithms of Facebook and features of Facebook that allow campaign content to be spread to candidate's followers and Facebook users connected to the candidate's Facebook page in one way or another. The constant dissemination of campaign messages on candidate's Facebook page was able to establish and develop a direct, informal, individualistic and close relationship between the candidates and followers to the extent that followers were able to engage with candidate's campaign throughout the election campaign. Therefore, receiving campaign message on Facebook could make followers felt 'as if it was something spoken by a friend.'

With the upcoming general election in Thailand expected to be in early 2019, the findings of the current research on digital vote-canvassing network during the 2013 Bangkok gubernatorial election does not only add to the growing literature on the use of SNSs for election campaign in Thailand, but also suggests that the function of digital vote-canvassing network has the potential for Facebook users to establish and develop their own network and relationship with their followers, which efficient management of digital vote-canvassing network could lead to political change or change in leadership.

It must be acknowledged that the data from Facebook captured for content analysis was not done during the election campaign, it was done retrospectively. After several attempts to find a method and software to capture and extract data from Facebook about six months after the 2013 Bangkok gubernatorial election campaign that the researcher found the (recently released) NCapture tool in Nvivo 10 to extract data from SNSs for analysis. Consequently, some Facebook data may be missing from the content analysis as it is unknown how long Facebook retains user's data posts and 
photographs, and other content may be missing due to Facebook's internal operations, algorithms and changing privacy settings over time. Also, the researcher was not able to contact all candidates in the 2013 Bangkok gubernatorial election for interview and to conduct observation studies with all the candidates, but believes that the interviews conducted corroborate one another sufficiently to establish clear insight into the issues discussed.

\section{Acknowledgement}

This paper was part of my Ph.D thesis titled: “'As if it was something spoken by a friend': Political Public Relations and Digital Vote-canvassing Network via Facebook during the 2013 Bangkok Gubernatorial Election campaign", which was fully funded by The University of Nottingham. I would like to thank my two Ph.D supervisors, Associate Professor Dr. Michael Connors and Assistant Professor Dr. Tessa Houghton for their feedback.

\section{References}

Baym, N. K. (2010). Personal Connections in The Digital Age. Cambridge: Polity Press. Bimber, B. (2014). Digital Media in the Obama Campaigns of 2008 and 2012: Adaptation to the Personalized Political Communication Environment. Journal of Information Technology \& Politics, 11, pp. 130-150.

Blumler, J. G., \& Kavanagh, D. (1999). The Third Age of Political Communication: Influences and Features. Political Communication, 16, pp. 209-230.

Boyd, D. M., \& Ellison, N. B. (2008). Social Network Sites: Definition, History, nd Scholarship. Journal of Computer-Mediated Communication, 13, pp. 210-230.

Braun, V., \& Clarke, V. (2013). Successful Qualitative Research. London: Sage.

Burnham, P., Gilland, K., Grant, W., \& Layton-Henry, Z. (2004). Research Methods in Politics. Hampshire: Palgrave Macmillan.

Callahan, W. A., \& McCargo, D. (1996). Vote-buying in Thailand's Northeast: The July 1995 General Election. Asian Survey, 36(4), pp. 376-392.

Chattharakul, A. (2010). Thai Electoral Campaigning: Vote-Canvassing Networks and Hybrid Voting. Journal of Current Southeast Asian Affairs, 29(4), pp. 67-95.

Chantornvong, S. (1993). เลือกตั้งวิกฤต: ปัญหาและทางออก [Thai Elections in Crisis: Problems and Solutions]. Bangkok: Kopfai Publishing. 
Chongkolrattanaporn, T., \& Combs, H. (2014). Thai Citizens' Utilization of Social Media Communications Devices During the Bangkok Governor Campaign in 2013. In Proceedings of American Society of Business and Behavioral Sciences (pp. 164170).

Copeland, L., \& Römmele, A. (2014). Beyond The Base? Political Parties, Citizen Activists, and Digital Media Use in the 2009 German Federal Election Campaign. Journal of Information Technology \& Politics, 11, pp. 169-185.

Dimitrova, D., \& Bystrom, D. (2013). The Effects of social Media on Political Participation and candidate Image Evaluations in the 2012 Iowa Caucuses. American Behavioral Scientist, 57(11), pp. 1568-1583.

Dubrofsky, R. E. (2011). Surveillance on reality television and Facebook: From Authenticity to Flowing Data. Communication Theory, 21(2), pp. 111-129.

Edgerly, S., Bode, L., Kim, Y. M., \& Shah, D. V. (2013). Campaigns Go Social: Are Facebook, YouTube and Twitter Changing Elections? In T. N. Ridout (Ed.), New Directions in Media and Politics (pp. 82-99). New York: Routledge.

Goodnow, T. (2013). Facing Off: A Comparative Analysis of Obama and Romney Facebook Timeline Photographs. American Behavioral Scientist, 57(11), pp. 1584-1595.

Grabe, M. E., \& Bucy, E. P. (2013). Image Bite Analysis of Political Visuals: Understanding the Visual Framing Process in Election News. In E. P. Bucy \& R. L. Holbert (Eds.), The Sourcebook for Political Communication Research: Methods, Measures, and Analytical Techniques (pp. 209-237). New York: Routledge.

Granovetter, M. S. (1973). The Strength of Weak Ties. American Journal of Sociology, 78(6), pp. 1360-1380.

Grbich, C. (2013). Qualitative Data Analysis: An Introduction. London: Sage.

Gillham, B. (2000). The Research Interview. London: Continuum.

Hansen, K. M., \& Kosiara-Pedersen, K. (2014). Cyber-campaigning in Denmark: Application and Effects of Candidate Campaigning. Journal of Information Technology \& Politics, 11(2), pp. 206-219.

Humphreys, L. (2011). Who's watching Whom? A Study of interactive Technology and Surveillance. Journal of Communication, 61(4), pp.575-595.

Hutton, J. G. (1999). The Definition, Dimensions, and Domain of Public Relations. Public Relations Review, 25(2), pp.199-214. 
Jenkins, H., Ford, S., \& Green, J. (2013). Spreadable Media: Creating Value and Meaning in A Networked Culture. New York: New York University Press.

Jewitt, C. (2009). An Introduction to Multimodality. In C. Jewitt (Ed.), The Routledge Handbook of Multimodal Analysis (pp. 14-27). New York: Routledge.

Katz, E., \& Lazarsfeld, P. F. (1955). Personal Influence: The Part Played by People in the Flow of Mass Communication. New Brunswick, New Jersey: The Free Press.

Kent, M. L. (2010). Directions in Social Media for Professionals and Scholars. In R. L. Heath (Ed.), The SAGE Handbook of Public Relations (pp. 643-656). Thousand Oaks, California: Sage.

Kress, G., \& Leeuwen, T. Van. (2006). Reading Images: The Grammar of Visual Design (2nd ed.). New York: Routledge.

Laothamatas. Anek. (1997). Development and Democratization: A Theoretical Introduction with Reference to the Southeast Asian and East Asian Cases. In Anek Laothamatas (Ed.), Democratization in Southeast and East Asia (pp. 1-20). Singapore: Institute of Southeast Asian Studies.

. (1996). A Tale of Two Democracies: Conflicting Perceptions of Elections and Democracy in Thailand. In R. H. Taylor (Ed.), The Politics of Elections in Southeast Asia (pp. 201-223). Washington, D.C.: Woodrow Wilson Center Press.

Marcinkowski, F., \& Metag, J. (2014). Why Do Candidates Use Online Media in Constituency Campaigning? An Application of the Theory of Planned Behavior. Journal of Information Technology \& Politics, 11(2), pp. 151-168.

Miller, M. (2011). Facebook for Grown-Ups: Use Facebook to Reconnect with Old Friends, Family, and Co-Workers (2nd ed.). Que Publishing.

Norris, P., \& Curtice, J. (2008). Getting the Message Out: A Two-Step Model of the Role of the Internet in Campaign Communication Flows During the 2005 British General Election. Journal of Information Technology and Politics, 4(4), pp. 3-13.

Ockey, J. (2004). Making Democracy: Leadership, Class, Gender, and Political Participation in Thailand. Chiang Mai: Silkworm Books.

Potter, W. J. (2012). Media Effects. California: Sage.

Pratheepwatanawong, M. (2018) 'Uses of Social Networking Sites as A Development of Political Communication and election Campaigns in Thailand'. In Morakot Meyer and Zhu Tingshu (eds), Multicultural ASEAN: Diversity in Identity, Language, Memory and Media (eds) (pp.65-90). Bangkok: Multicultural ASEAN 
Center Project, Research Institute for Languages and Cultures of Asia, Mahidol University.

Samakkarn, S. (1994). พี่น้อง [Phi Nong]. In Suwanna Satha-Anand \& Nuangnoi Boonyanate (Eds.), คำ: ร่องรอยความคิด ความเชื่อไทย [Words: Trace Thinking, Thai Belief] (pp. 164-171). Bangkok: Chulalongkorn University Press.

Stokes-Brown, A. (2012). Minority Candidates and the Changing Landscape of Campaigns in the Twenty-First Century. In R. J. Semiatin (Ed.), Campaigns on the Cutting Edge (pp. 211-225). London: Sage.

Strandberg, K. (2013). A Social Media Revolution or Just A Case of History Repeating Itself? The Use of Social Media in the 2011 Finnish parliamentary Elections. New Media and Society, 0(0), pp. 1-19.

Strömbäck, J., \& Kiousis, S. (2011). Political Public Relations: Defining and Mapping An Emergent Field. In J. Strömbäck \& S. Kiousis (Eds.), Political Public Relations: Principles and Applications (pp. 1-32). New York: Routledge.

Supadhiloke, B. (2015). How Opinion Polls Affect Voting in Bangkok's Gubernatorial Election. Asian Journal of Communication, 25(2), pp. 135-161.

Taveesin, N., \& Brown, W. (2006). The Use of Communication Technology in Thailand's Political Process. Asian Journal of Communication, 16(1), pp. 59-78.

Thananithichot, S. (2012). Political Engagement and Participation of Thai Citizens: the Rural-Urban Disparity. Contemporary Politics, 18(1), pp. 87-108.

Maisrikrod, S \& McCargo, D. (1997). Electoral Politics: Commercialisation and Exclusion. In Political Change in Thailand: Democracy and Participation (pp. 132148). London: Routledge.

Sweetser, K. D. (2011). Digital Political Public Relations. In J. Strömbäck \& S. Kiousis (Eds.), Political Public Relations: Principles and Applications (pp. 293-313). New York: Routledge.

Van Dijck, J. (2013). The Culture of Connectivity: A Critical History of Social Media. Oxford: Oxford University Press. (2006). The Network Society. London: Sage. 